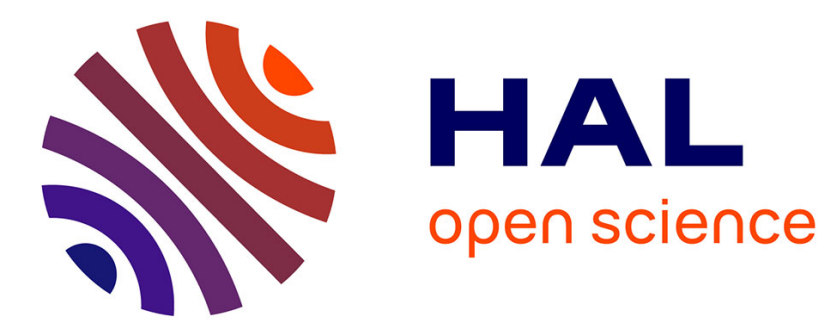

\title{
Delicate Balance among Three Ferroic Polymorphic Phases in BiFeO3-BiMnO3-PbTiO3
}

\author{
C.M. Fernández-Posada, A. Castro, O. Peña, M. Alguero, H. Amorín
}

\section{To cite this version:}

C.M. Fernández-Posada, A. Castro, O. Peña, M. Alguero, H. Amorín. Delicate Balance among Three Ferroic Polymorphic Phases in BiFeO3-BiMnO3-PbTiO3. Journal of Physical Chemistry C, 2019, 123 (20), pp.13063-13073. 10.1021/acs.jpcc.9b02645 . hal-02161313

HAL Id: hal-02161313 https://hal-univ-rennes1.archives-ouvertes.fr/hal-02161313

Submitted on 21 Jun 2019

HAL is a multi-disciplinary open access archive for the deposit and dissemination of scientific research documents, whether they are published or not. The documents may come from teaching and research institutions in France or abroad, or from public or private research centers.
L'archive ouverte pluridisciplinaire HAL, est destinée au dépôt et à la diffusion de documents scientifiques de niveau recherche, publiés ou non, émanant des établissements d'enseignement et de recherche français ou étrangers, des laboratoires publics ou privés. 


\section{INTRODUCTION}

Multiferroism refers to materials in which two or more types of primary ferroic ordering are present in the same phase, being of particular interest those with coexistence of the electrical and magnetic orders. ${ }^{1-3}$ These materials develop a linear electrical polarization (magnetization) in response to an applied magnetic (electric) field, and are also liable to show non-linear coupling phenomena like crossed magnetoelectric switching. ${ }^{4}$ This could enable a novel nonvolatile random access memory, that is, a low-power, high-density information storage that would combine fast electrical WRITE/magnetic READ operations, among a number of new potentially disruptive technologies like voltage-controlled spintronic devices, uncooled magnetic sensors, or electrically-tunable magnetic microwave components. ${ }^{5-7}$

A major research activity is concentrated on single-phase multiferroics, particularly on those that might exhibit such coupling at room temperature, among which $\mathrm{ABO}_{3}$ perovskite oxides stand out. This is because multiferroicity can be chemically engineered on a site-by-site basis, by placing ferroelectrically and magnetically active cations in $A$ - and $B$-site, respectively, so that the two ferroic orders develop independently. ${ }^{8}$ This is the case of $\mathrm{BiFeO}_{3}$ and $\mathrm{BiMnO}_{3},{ }^{9,10}$ two systems at the cutting edge of research, particularly in the context of strained films, ${ }^{11,12}$ and of the solid solutions they form with $\mathrm{PbTiO}_{3} \cdot{ }^{13,14}$ Interest in solid solutions exhibiting coexistence of multiferroic polymorphs at the morphotropic phase boundary (MPB) is increasing, not only for property enhancement takes place but also for phase-change functional responses can be obtained. ${ }^{15,16}$

Strong phase-change magnetoelectric responses were first anticipated in the perovskite $\mathrm{BiFeO}_{3}-\mathrm{BiCoO}_{3}$ binary system by a first-principles investigation, associated with the coexistence of multiferroic phases of rhombohedral $R 3 C$ and tetragonal
P4mm symmetries at the MPB. ${ }^{17}$ Mechanism proposed was the discrete rotation of magnetization following that of polarization under the electric field, associated with an electric field induced transformation between the two multiferroic polymorphs. ${ }^{18}$ Phase-change magnetoelectric phenomena have also been found in other perovskites like in Nd substituted $\mathrm{BiFeO}_{3}$, associated this time to an electric field-induced orthorhombic Pnma to rhombohedral $R 3 c$ phase transition. ${ }^{19}$ Pressure-induced transformation between multiferroic polymorphs has also been reported, like in La substituted $\mathrm{BiFeO}_{3} .{ }^{20}$ In this case, a transition from rhombohedral/polar R3c to orthorhombic/antipolar Pbam phases was found under high pressure, and strong effects on properties were anticipated. Therefore, phase-change functional responses might be a general property of multiferroic MPBs. ${ }^{21}$

We have recently reported the occurrence of phase-change magnetoelectric phenomena for a specific composition of the $\mathrm{BiFeO}_{3}-\mathrm{BiMnO}_{3}-\mathrm{PbTiO}_{3}$ ternary system, for which coexistence of phases with monoclinic $C c$ and tetragonal $P 4 \mathrm{~mm}$ symmetries was found. ${ }^{22}$ In this material, both polymorphs are ferroelectric and antiferromagnetic (AFM), yet a weak ferromagnetic component appears within the $C c$ phase, as a result of a spin reorientation (SRO) transition within its AFM state. ${ }^{23}$ Room-temperature magnetoelectricity is obtained, not only due to an electric field driven phase-change between the two multiferroic polymorphs, but also by the presence of a transverse lattice softening within the monoclinic phase that gives rise to linear magnetoelectric effect. ${ }^{22}$ The latter phenomenology would be analogous to that described in high-sensitivity MPB ferroelectrics, which is responsible for the very-high piezoelectric responses. ${ }^{24}$ Indeed, a theoretical study has pointed out to the possibility of obtaining enhanced magnetoelectric responses at multiferroic analogues associated with this lattice transverse softening. ${ }^{25}$ 
A close interplay among the crystal structure, the defect chemistry and multiferroic properties of phases has been recently demonstrated for compositions of this ternary system, yet at a different MPB. ${ }^{26}$ Namely, phase coexistence of a ferroelectric $P 4 \mathrm{~mm}$ with an antiferroelectric Pnma polymorph was found in $\mathrm{Bi}_{0.4} \mathrm{~Pb}_{0.6} \mathrm{Mn}_{0.4} \mathrm{Ti}_{0.6} \mathrm{O}_{3}$, where both showed spin-glass-like magnetic behavior. This type of polar/antipolar MPB has also been proposed to engineer new high-sensitivity ferro-/piezoelectrics. ${ }^{27}$ Besides, large phase-change magnetoelectric responses have been anticipated as a result of an antipolar to polar transition. ${ }^{19}$ Point defects are thought to be behind changes in the crystal structure reported by different groups with the processing conditions used, as well as with thermal history. ${ }^{28-30}$

This work provides a comprehensive analysis of the delicate balance between polymorphs along the line of MPBs present in the $\mathrm{BiFeO}_{3}-\mathrm{BiMnO}_{3}-\mathrm{PbTiO}_{3}$ ternary system, ${ }^{31}$ its relation to the defect chemistry, and its repercussion in the multiferroic properties. Moreover, a grain size effect, not described before, is revealed and discussed accordingly. Materials chosen are compositionally located in the region where the evolution from $C c / P 4 m m$-type to $P n m a / P 4 m m$-type MPBs takes place, at which coexistence of up to three different polymorphs can be obtained. These could be an alternative to $\mathrm{BiFeO}_{3}-\mathrm{BiCoO}_{3}$ for room-temperature phase-change magnetoelectric effect, with the advantage that they can be easily obtained by mechanochemical methods. The high chemical homogeneity provided by this synthesis technique has been key to uncover the MPB phases, and more importantly, to establish their multiferroic features. High-resolution x-ray diffraction (XRD) has allowed assessing the symmetry of the phases involved. Results of the dielectric and magnetic characterizations have allowed establishing the structure-property relationships, and to discuss the key role of the defect chemistry on the polymorph stabilized at room temperature.

\section{EXPERIMENTAL SECTION}

Nanocrystalline powders with perovskite structure were obtained by mechanosynthesis in a high energy planetary mill (Fritsch Pulverisette 6) operating at $300 \mathrm{rpm}$ for $24 \mathrm{~h}$ in tungsten carbide milling media, from stoichiometric mixtures of analytical grade oxides $\mathrm{Bi}_{2} \mathrm{O}_{3}$ (Aldrich, 99.9\% pure), $\mathrm{PbO}$ (Merck, 99\%), $\mathrm{Fe}_{2} \mathrm{O}_{3}$ (Cerac, 99.9\%), $\mathrm{TiO}_{2}$ (anatase, Cerac, 99\%) and $\mathrm{Mn}_{2} \mathrm{O}_{3}$ (Aldrich, 99\%). Details of the procedure and of the mechanisms that take place during mechanical treatments can be found elsewhere. ${ }^{31}$ The milling conditions were tailored so as negligible contamination levels resulted. Compositions prepared respond to the general formula $\mathrm{Bi}_{\mathrm{x}+\mathrm{y}} \mathrm{Pb}_{1-\mathrm{x}-\mathrm{y}} \mathrm{Fe}_{\mathrm{x}} \mathrm{Mn}_{\mathrm{y}} \mathrm{Ti}_{1-\mathrm{x}-}$ $\mathrm{y}_{3}$, with $x=0.52 ; y=0.1$ (labeled 1), $x=0.47 ; y=0.15$ (2), $x$ $=0.47 ; y=0.11$ (3), and $x=0.7 ; y=0.05$ (4). Their actual locations in the phase diagram of the ternary system are indicated in Fig. 1. Mechanosynthesized powders were thermally treated at $950{ }^{\circ} \mathrm{C}$ for $12 \mathrm{~h}$ to increase crystal sizes for the structural characterization. Two cooling profiles were used: (i) a slow cooling with rate of $3{ }^{\circ} \mathrm{C} \mathrm{min}{ }^{-1}$ and (ii) a fast cooling (quenching) in air down to room temperature.

Crystal structure of powdered samples was assessed by XRD. A highly accurate two-axis diffractometer with a Rigaku RAHF18 rotating anode generator, in Bragg-Brentano geometry and coupled with a furnace, was used in the range of $15^{\circ}$ to $150^{\circ}$

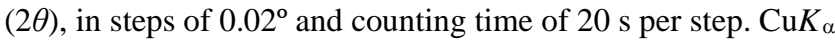
doublet $(\lambda=1.5418 \AA$ ) was used in the experiments, and a monochromator producing $\mathrm{CuK}_{\beta}(\lambda=1.39225 \AA)$ was occasionally used for higher resolution. Diffraction profiles were analyzed by the Rietveld method implemented in Jana2006 package. ${ }^{32}$

Magnetic properties were characterized with a Quantum Design MPMS-XL5 SQUID magnetometer. Powdered samples were cooled down to $2 \mathrm{~K}$ under zero field and then a magnetic field of 500 Oe was applied and maintained during a heating/cooling (ZFC/FC) cycle up to $400 \mathrm{~K}$.

Ceramic materials for the dielectric characterization were prepared by direct hot-pressing of the nanocrystalline powders. Temperature was varied between 1000 and $800{ }^{\circ} \mathrm{C}$ in order to obtain a range of microstructures with decreasing grain size. A holding time of $1 \mathrm{~h}$ and a pressure of $60 \mathrm{MPa}$ were selected, while heating/cooling rates of $3{ }^{\circ} \mathrm{C} \mathrm{min}^{-1}$ were used. Archimedes' method was used to measure the density of the sintered pellets, and final densification levels above $99 \%$ were systematically attained.

Ceramic microstructure was characterized by field-emission scanning electron microscopy with a NovaTM NanoSEM 230 apparatus. Samples were polished to mirror finish with $\mathrm{Al}_{2} \mathrm{O}_{3}$ suspensions down to $0.1 \mu \mathrm{m}$, and thermally etched at $800{ }^{\circ} \mathrm{C}$ for $20 \mathrm{~min}$ and quenched in air down to room temperature to reveal the grain boundaries. A series of very dense microstructures with tailored average grain size across the submicron range, down to the nanoscale was obtained, as shown in Fig. 2 for ceramics of composition 1 , taken by way of example. Note the absence of residual porosity or secondary phases. The evolution of the average grain size with hot-pressing temperature suggests a single mechanism of grain growth [Fig. 2(d)].

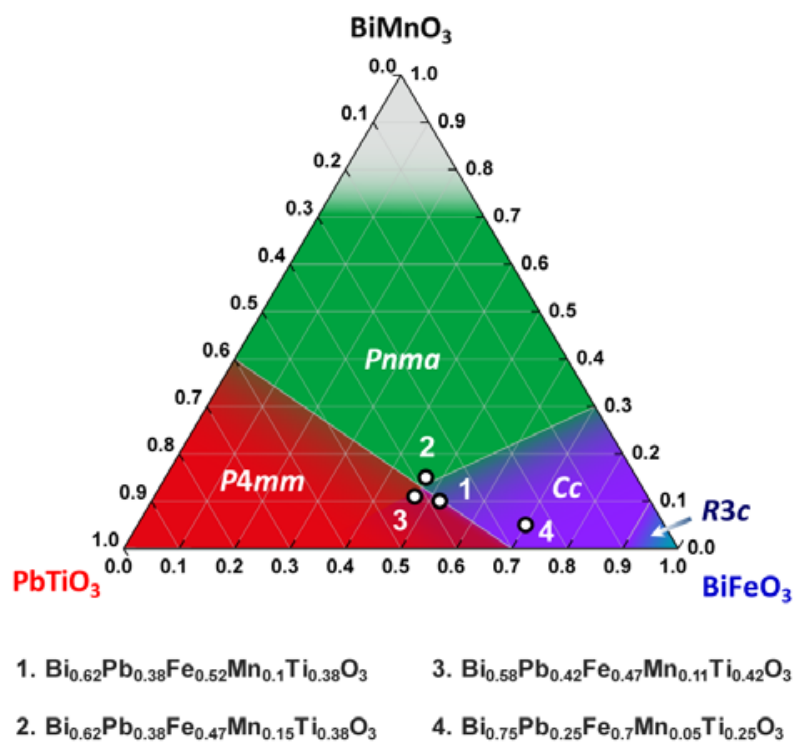

Figure 1. Schematic phase diagram of the $\mathrm{BiFeO}_{3}-\mathrm{BiMnO}_{3}-$ $\mathrm{PbTiO}_{3}$ ternary system, where MPB regions are highlighted and nominal compositions under study indicated with closed circles. 

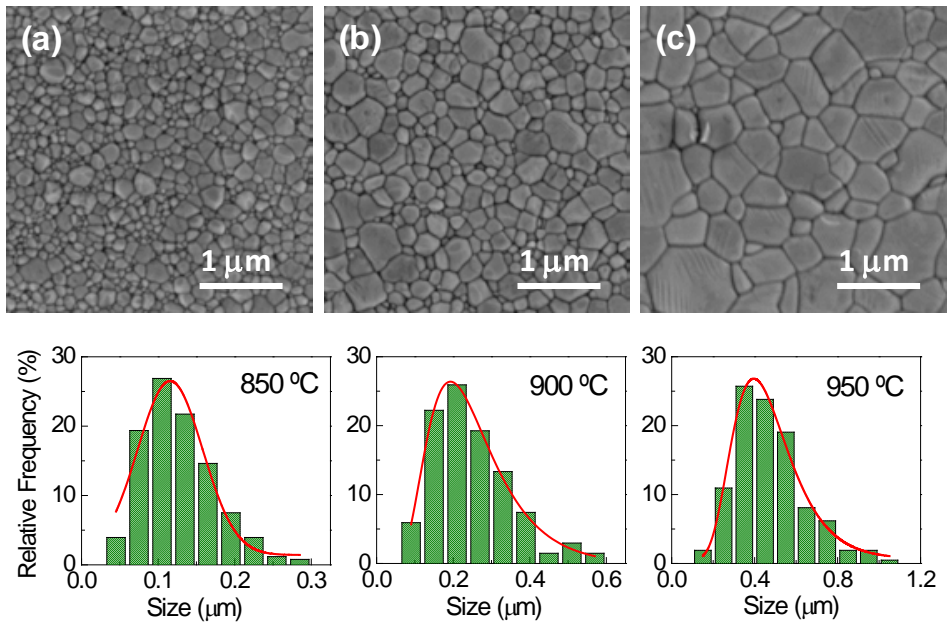

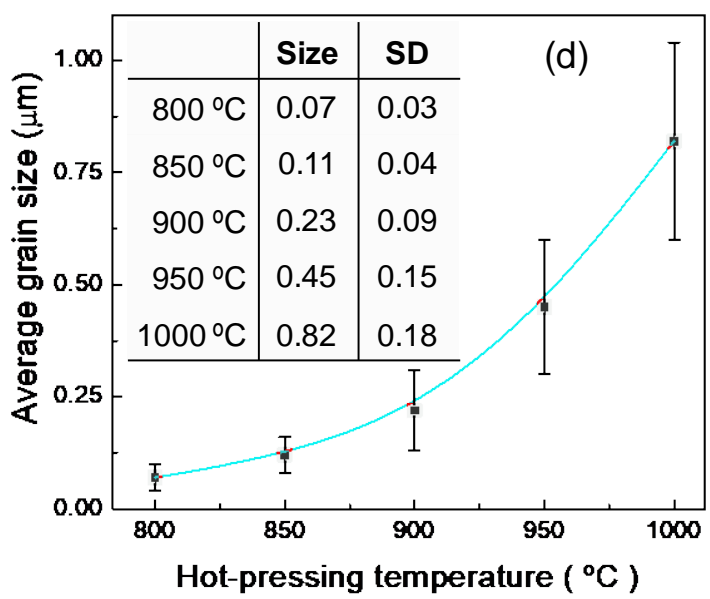

Figure 2. Scanning electron microscopy micrographs of ceramics of composition $1\left(\mathrm{Bi}_{0.62} \mathrm{~Pb}_{0.38} \mathrm{Fe}_{0.52} \mathrm{Mn}_{0.1} \mathrm{Ti}_{0.38} \mathrm{O}_{3}\right)$ obtained by hot-pressing at (a) $850{ }^{\circ} \mathrm{C}$, (b) $900^{\circ} \mathrm{C}$ and (c) $950{ }^{\circ} \mathrm{C}$, along with the resulting size distributions in each case. (d) Evolution of the average grain size with the sintering temperature (standard deviations, SD, are given as error bars). Grain sizes $(\mu \mathrm{m})$ are given in the inserted table.

Electrical properties were measured on ceramic discs, on which Ag electrodes were painted and annealed at $750{ }^{\circ} \mathrm{C}$ for 1 h. Dependences of the dielectric permittivity and losses on temperature were dynamically measured between room temperature and $700{ }^{\circ} \mathrm{C}$ under heating/cooling cycles at $1.5^{\circ} \mathrm{C} \mathrm{min}^{-1}$ with a HP4284A precision LCR Meter at several frequencies between $100 \mathrm{~Hz}-1 \mathrm{MHz}$.

\section{RESULTS AND DISCUSSION}

3.1. Structural Characterization. Figure 3 shows the XRD patterns of mechanosynthesized powders corresponding to the MPB compositions displayed in Fig. 1, after thermal treatment at $950{ }^{\circ} \mathrm{C} / 12 \mathrm{~h}$ followed by two different cooling profiles, that is, slow cooling (black patterns) and quenching (red patterns). In the composition $1\left(\mathrm{Bi}_{0.62} \mathrm{~Pb}_{0.38} \mathrm{Fe}_{0.52} \mathrm{Mn}_{0.1} \mathrm{Ti}_{0.38} \mathrm{O}_{3}\right)$, both powders crystallized into perovskite-type structure (no secondary phase was found), and peak splitting clearly evidences that phase coexistence between polymorphs of different symmetries occurs [Fig. 3(a)]. In the quenched material, this coexistence involves a tetragonal polymorph and a second one that might be either rhombohedral or monoclinic, whereas the slowly cooled sample showed broad/asymmetric diffraction peaks that also indicate phase coexistence, though actual symmetries, in this case, cannot be directly assessed.

Composition $2 \quad\left(\mathrm{Bi}_{0.62} \mathrm{~Pb}_{0.38} \mathrm{Fe}_{0.47} \mathrm{Mn}_{0.15} \mathrm{Ti}_{0.38} \mathrm{O}_{3}\right) \quad$ also showed the powders crystallized into perovskite-type structure [Fig. 3(b)], yet a clear phase coexistence was only evidenced in the quenched material, which also seems to involve tetragonal and rhombohedral (or monoclinic) polymorphs, whereas a single polymorph that appears to be cubic (or likely pseudo-cubic) was obtained after slow cooling. On the contrary, composition $3\left(\mathrm{Bi}_{0.58} \mathrm{~Pb}_{0.42} \mathrm{Fe}_{0.47} \mathrm{Mn}_{0.11} \mathrm{Ti}_{0.42} \mathrm{O}_{3}\right)$ seems to be fully tetragonal after quenching, whereas the slowly cooled material showed broad/asymmetric diffraction peaks [Fig. 3(c)], like those for composition 1. Results thus confirm these three compositions are at or nearby the line of MPBs in the ternary system, and show that different polymorphs can be stabilized in the same material depending on the cooling profile used.

Diffraction profiles were analyzed by the Rietveld method to establish the actual crystal symmetry of the coexisting polymorphs, for which tetragonal $\mathrm{P} 4 \mathrm{~mm}$ space group of $\mathrm{PbTiO}_{3}$ along with the rhombohedral $R 3 c$ of $\mathrm{BiFeO}_{3}$ or monoclinic $C c$ symmetries (reported for $\mathrm{BiFeO}_{3}-\mathrm{PbTiO}_{3}$ system) ${ }^{28}$ were chosen as structural models in the refinements of the quenched samples. However, differences found on the statistical parameters resulting from models involving either $R 3 c$ or $C c$ were not large enough to fully discriminate which of these two symmetries coexists with the $P 4 \mathrm{~mm}$ one. This is due to the complexity of the profiles resulting from the phase coexistence, a handicap for the successful application of the Rietveld method to MPB compositions, further complicated by the crystal stresses present due to the difference in transition strain between the polymorphs and anisotropy factors due to ferroelectricity.

The study was then carried out in a composition with nominal formula $\mathrm{Bi}_{0.75} \mathrm{~Pb}_{0.25} \mathrm{Fe}_{0.7} \mathrm{Mn}_{0.05} \mathrm{Ti}_{0.25} \mathrm{O}_{3}$ (labeled 4), which is located well within the pseudo-rhombohedral region of the phase diagram, and away from the line of MPBs. As expected, only one polymorph is present in the patterns of samples either slowly cooled or quenched, as shown in Fig. 4(a) for the slowly cooled one. The absence of the tetragonal phase, in this case, avoids the complexity of refining patterns with phase coexistence. The profile was refined for both $R 3 c$ and $C c$ symmetries, among others, and results are given in Table 1 . It can be seen that statistical parameters are slightly better for the Cc space group, in particular GOF indicator and $R_{\text {Bragg }}$ factor.

The best agreement for the $C c$ phase is also evident when one specifically analyses the refined profiles across the diffraction peaks, such as $(112)_{\mathrm{p}}$ and $(103)_{\mathrm{p}}$ ones (referring to pseudocubic indices), as illustrated in Figs. 4(b) and 4(c). It is clear that the fit using $R 3 C$ symmetry is not satisfactory, as the anomalous peak broadening is not consistent with considering them as doublets, as expected for this symmetry. This confirms that the polymorph in coexistence with the tetragonal one is most likely the monoclinic $\mathrm{Cc}$ in these $\mathrm{BiFeO}_{3}$-rich compositions, so that a $C \mathrm{C} / \mathrm{P} 4 \mathrm{~mm}$-type MPB would be obtained. It should be taken into account the greater number of structural degrees of freedom that the $C c$ structure introduces in the refinement, as compared to the $R 3 c$ one. Indeed, a controversy persists regarding the actual existence of the $C c$ polymorph in the $\mathrm{BiFeO}_{3}-\mathrm{PbTiO}_{3}$ binary system. ${ }^{10,22,28}$ However, the presence of transverse lattice softening and a magnetic SRO transition, ${ }^{14,23}$ both phenomena characteristic of the monoclinic symmetry, seems to confirm the presence of the $C c$ phase in the ternary system. 

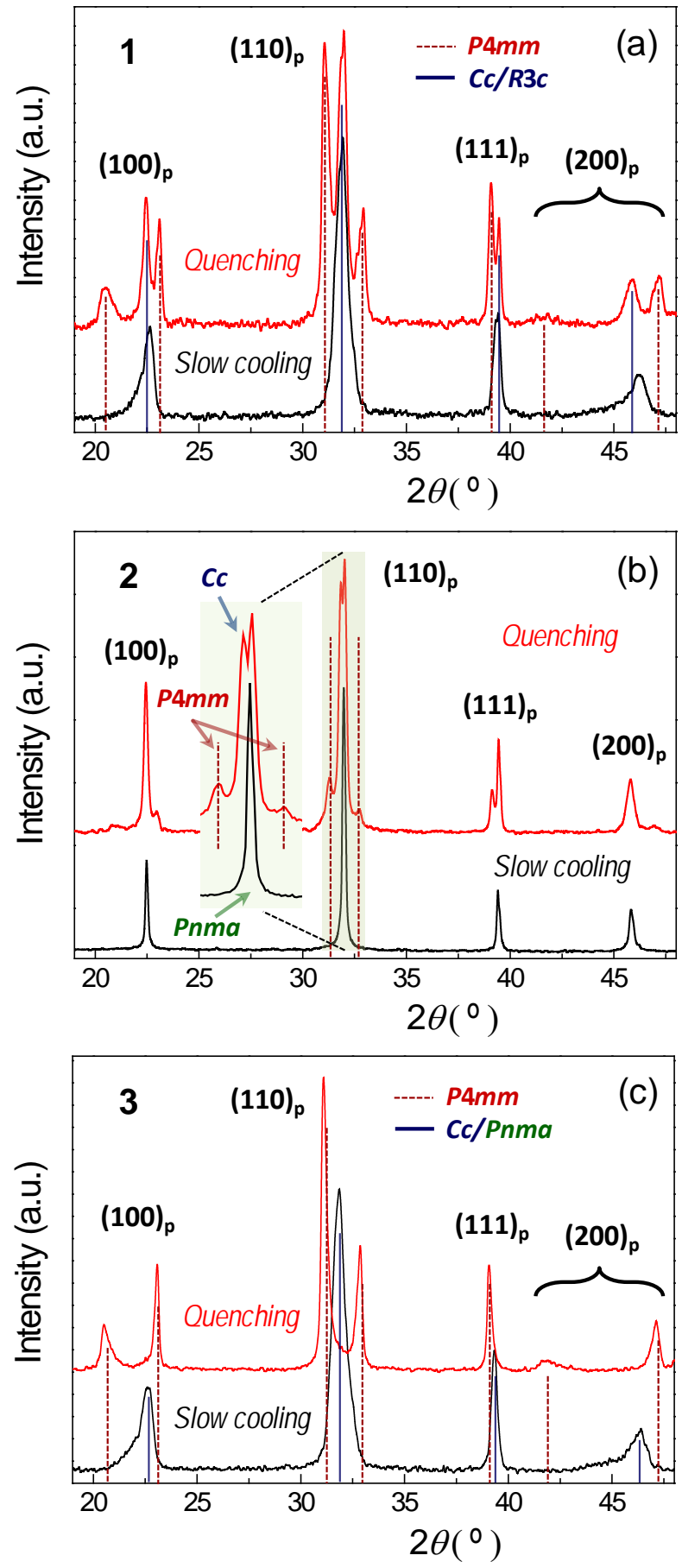

Figure 3. XRD patterns with $\mathrm{Cu} K_{\alpha}$ at room temperature on powder samples thermally treated at $950{ }^{\circ} \mathrm{C}$ and using different cooling rates: slow cooling (black pattern) and quenching (red pattern), corresponding to compositions (a) $1-\mathrm{Bi}_{0.62} \mathrm{~Pb}_{0.38} \mathrm{Fe}_{0.52} \mathrm{Mn}_{0.1} \mathrm{Ti}_{0.38} \mathrm{O}_{3}$, (b) $2-\mathrm{Bi}_{0.62} \mathrm{~Pb}_{0.38} \mathrm{Fe}_{0.47} \mathrm{Mn}_{0.15} \mathrm{Ti}_{0.38} \mathrm{O}_{3}$, (c) $3-\mathrm{Bi}_{0.58} \mathrm{~Pb}_{0.42}$ $\mathrm{Fe}_{0.47} \mathrm{Mn}_{0.11} \mathrm{Ti}_{0.42} \mathrm{O}_{3}$. Miller indices are for pseudo-cubic symmetry.

Additionally, the symmetry of the pseudo-cubic polymorph that resulted from slow cooling of composition 2 was also investigated. In this case, orthorhombic Pnma space group, among others such as cubic $P m-3 m$ and monoclinic $C 2 / c$ or $C 2$ (typically reported for $\mathrm{BiMnO}_{3}$-based compositions), ${ }^{33}$ were chosen as structural models in the refinements. The best fit between the observed and calculated profiles was obtained for 

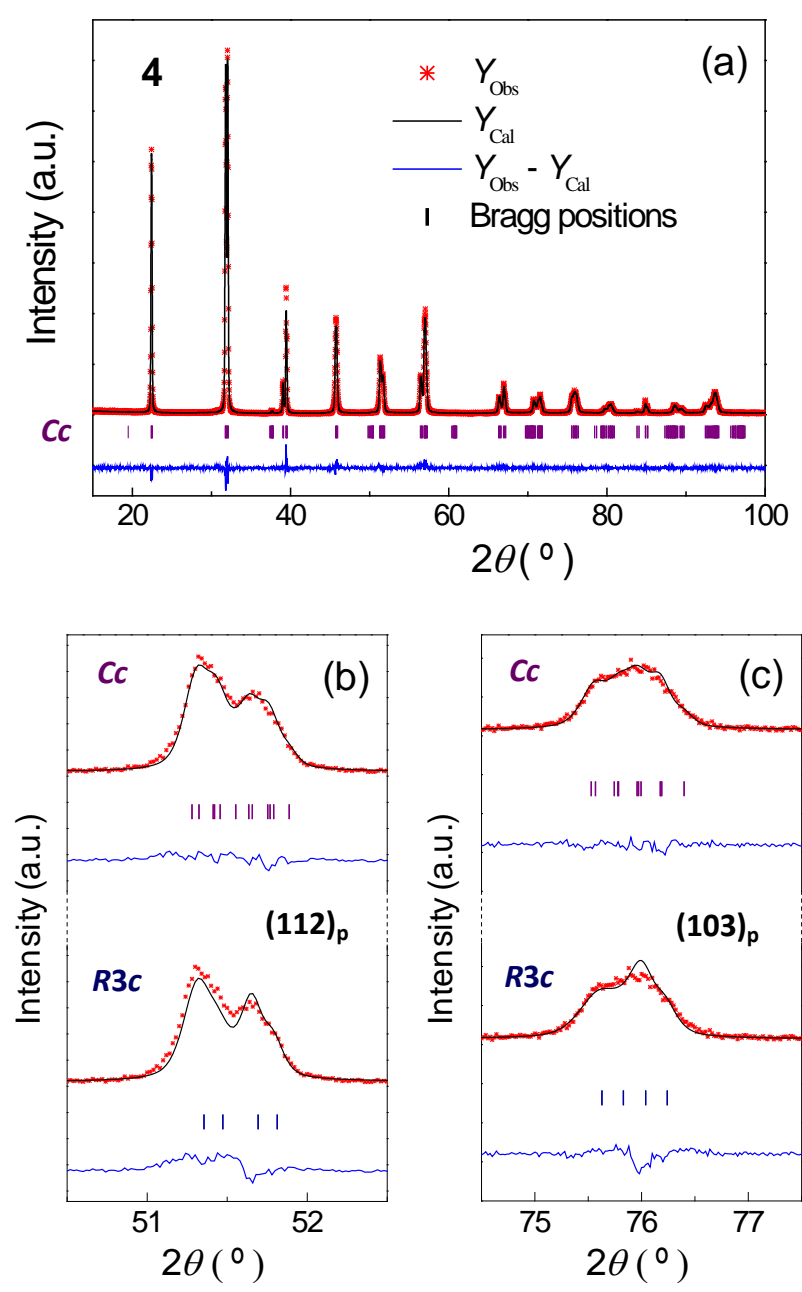

Figure 4. High-resolution XRD pattern using $\mathrm{Cu} K_{\alpha}$ on powder sample of composition $4\left(\mathrm{Bi}_{0.75} \mathrm{~Pb}_{0.25} \mathrm{Fe}_{0.7} \mathrm{Mn}_{0.05} \mathrm{Ti}_{0.25} \mathrm{O}_{3}\right)$ along with the Rietveld refinement using monoclinic Cc symmetry. Yobs and $Y_{\text {Cal }}$ refer to measured and calculated intensities, respectively. Rietveld refinements with $C c$ and rhombohedral $R 3 c$ symmetries across the (b) (112)p and (c) (103)p reflections (pseudo-cubic indices) are shown to illustrate the better agreement of $C c$ phase.

the Pnma symmetry, as shown in Fig. 5(a), though differences with the cubic $P m-3 m$ instead were not that large (GOF $=1.39$ for Pnma and 1.43 for $P m-3 m$ ). On the other hand, the quenched material showed the best fit from the model involving coexistence of $C c$ (92\%) and P4mm (8\%) phases, as shown in Fig. 5(b). The refined structural and statistical parameters of composition 2 are given in Table 2.

In order to deepen into the symmetry of this apparently pseudocubic polymorph in the slowly cooled sample of composition 2 , the temperature evolution of the perovskite phase was investigated. Figure 6 shows the XRD profiles around the $(110)_{\mathrm{p}}$ peak (referring to pseudocubic index) at increasing temperatures, along with the resulting temperature dependence of the lattice parameter assuming to be pseudocubic $\left(a_{\mathrm{ps}}\right)$. Two regions are clearly differentiated with a distinctive change of the thermal expansion rate at $\sim 500{ }^{\circ} \mathrm{C}$. A similar change of slope was reported for $\mathrm{Bi}_{0.4} \mathrm{~Pb}_{0.6} \mathrm{Mn}_{0.4} \mathrm{Ti}_{0.6} \mathrm{O}_{3}$ (with a Pnma/P4mmtype MPB), and associated with the transition from the orthorhombic Pnma towards the high-temperature parent phase, ${ }^{26}$ which turns out to be cubic $P m-3 m$ in most

Table 1. Results of the Rietveld refinements of $\mathrm{Bi}_{0.75} \mathrm{~Pb}_{0.25} \mathrm{Fe}_{0.7} \mathrm{Mn}_{0.05} \mathrm{Ti}_{0.25} \mathrm{O}_{3}$ sample (composition 4). ${ }^{a}$

\begin{tabular}{ccc} 
Space group & $R 3 c$ & $C c$ \\
\hline \multirow{2}{*}{ Statistical parameters } & $R_{\mathrm{wp}}=12.12 ; R_{\mathrm{p}}=8.97 ; R_{\mathrm{exp}}=9.18 ;$ & $R_{\mathrm{wp}}=11.19 ; R_{\mathrm{p}}=8.41 ; R_{\exp }=9.17 ;$ \\
& $R_{\mathrm{Bragg}}=6.06 ; \mathrm{GOF}=1.32$ & $R_{\text {Bragg }}=4.25 ; \mathrm{GOF}=1.22$ \\
Lattice parameters $(\AA)$ & $a=5.586(5) ; c=13.842(9)$ & $a=9.763(4) ; b=5.589(3) ;$ \\
& & $c=5.634(7) ; \beta=125.85(8)^{\circ}$ \\
\hline
\end{tabular}

Space group

$\begin{array}{cc}x & \mathrm{Bi} / \mathrm{Pb} \\ y & 0 \\ Z & 0.25 \\ B_{\text {eq }}\left(\AA^{2}\right) & 0\end{array}$

$\mathrm{Fe} / \mathrm{Mn} / \mathrm{Ti}$
$0.275(1)$
$0.243(1)$
$0.731(0)$
0.01

$\mathrm{Fe} / \mathrm{Mn} / \mathrm{Ti}$

$\mathrm{O} 1$

$0.044(2)$

$0.291(7)$

$0.460(2)$

1.50

$\mathrm{O} 2$
$0.327(5)$
$0.453(6)$
$0.033(7)$
1.50

O3

${ }^{a}$ Reliability factors ( $R$-factors) and goodness-of-fit indicator (GOF) are given for both rhombohedral $R 3 c$ and monoclinic $C c$ symmetries, while position coordinates $(x, y, z)$ and thermal parameters $\left(B_{\text {eq }}\right)$ are given for the $C c$ symmetry.

ferroelectric perovskites. ${ }^{34}$ Results, therefore, indicate the symmetry of this polymorph to be Pnma at room temperature.

The strong dependence of the phase coexistence on the thermal history in these MPB compositions is worth further discussion. A major role of the defect chemistry can be anticipated, in particular, of the oxygen vacancies generated by the different cooling profiles, and the resulting partial reduction/oxidation of the transition metal cations. ${ }^{35,36}$ This means that the equilibrium oxygen content during the thermal treatment might be frozen at room temperature by quenching, but a slow cooling provides more time for oxygen equilibrium, thus involving oxidation/reduction of cations like Fe and Mn. This would imply a change in the tolerance factor that might push the system across the MPB. The point defect equilibrium here can be expressed as:

$$
2 \mathrm{M}_{\mathrm{M}}^{\bullet}+\mathrm{O}_{\mathrm{O}}=2 \mathrm{M}_{\mathrm{M}}+\mathrm{V}_{\mathrm{O}}^{\bullet \bullet}+\frac{1}{2} \mathrm{O}_{2}(\mathrm{~g})
$$


where $\mathrm{M}_{\mathrm{M}}^{\bullet}$ refers to $(\mathrm{Fe} / \mathrm{Mn})^{4+}$ and $\mathrm{M}_{\mathrm{M}}$ to $(\mathrm{Fe} / \mathrm{Mn})^{3+}, \mathrm{V}_{\mathrm{O}}^{* \bullet}$ is an oxygen vacancy and $\mathrm{O}_{\mathrm{O}}$ is an oxygen anion.

Note the lattice expansion that resulted from the quenching treatment, so as the unit cell volume of the stabilized polymorph is about $0.33 \%$ and $2 \%$ higher than that obtained by slow cooling, in the compositions 2 and 3, respectively. This favored the formation of the Cc phase in the former and the $P 4 \mathrm{~mm}$ one in the latter. This chemical expansion can be understood from the difference in the ionic radii of the cations involved, and the resulting changes in the size of the $\mathrm{MO}_{6}$ octahedra. ${ }^{35}$ The smaller unit cell volume in both materials after the slow cooling suggests that chemical contraction due to Fe and Mn oxidation took place, whereas a frozen oxygen equilibrium state, achieved with the quenching, must hinder cations oxidation. ${ }^{26}$

It is worth summarizing the results of the structural characterizations before addressing the ferroic properties. Coexistence of the monoclinic Cc and tetragonal $P 4 \mathrm{~mm}$ polymorphs has been shown for compositions 1 and 3, while coexistence of all three Cc, P4mm and Pnma has been obtained for composition 2. Phase percentages can be varied by high-temperature treatments with tailored cooling profiles, so that the different polymorphs have been mostly isolated at room temperature: monoclinic Cc in powders of compositions 1 and 3 slowly cooled, orthorhombic Pnma in composition 2 slowly cooled, and tetragonal $\mathrm{P} 4 \mathrm{~mm}$ for composition 3 after quenching. This ensemble of samples with close compositions and tailored perovskite structure locates in a small region of the phase diagram around the line of MPBs, where the evolution from $C c / P 4 m m$-type to Pnma/P4mm-type takes place.
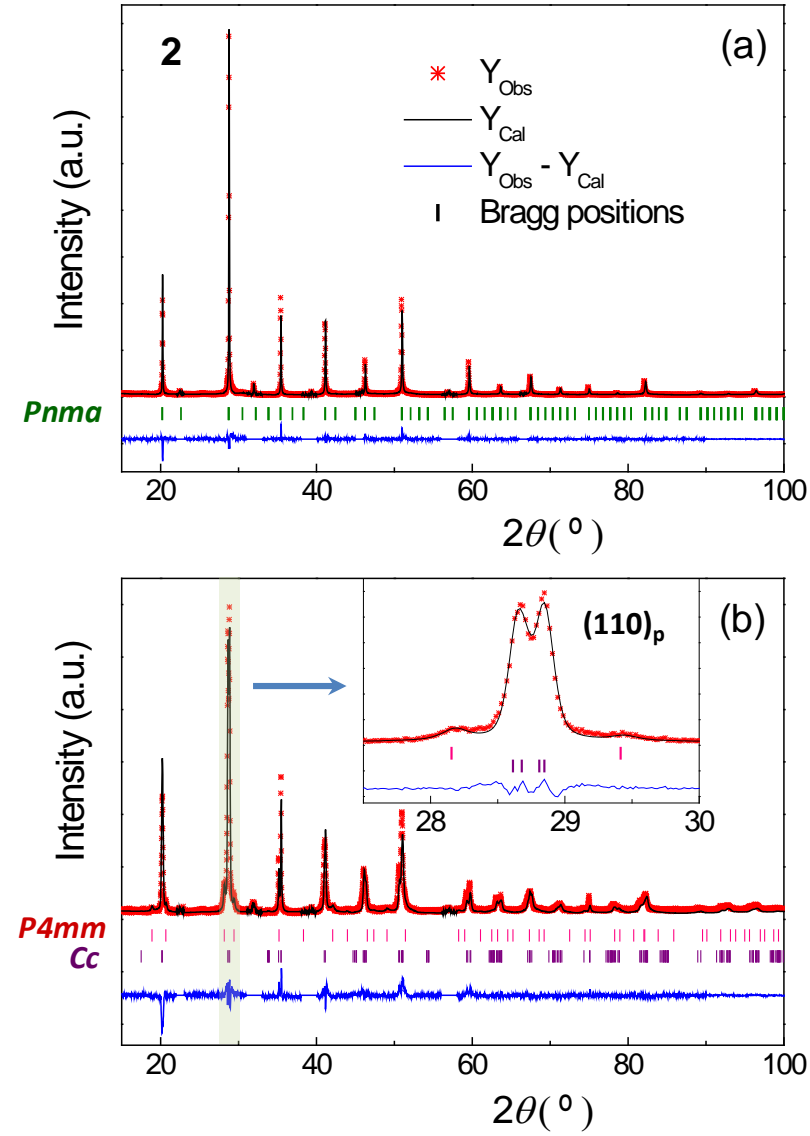

Figure 5. High-resolution XRD patterns using $\mathrm{Cu} K_{\beta}$ on powder samples of composition $2\left(\mathrm{Bi}_{0.62} \mathrm{~Pb}_{0.38} \mathrm{Fe}_{0.47} \mathrm{Mn}_{0.15} \mathrm{Ti}_{0.38} \mathrm{O}_{3}\right)$, after thermal treatment at $950{ }^{\circ} \mathrm{C}$ followed by (a) slow cooling and (b) quenching. Profiles were analyzed by the Rietveld method using (a) orthorhombic Pnma and (b) coexistence of monoclinic Cc and tetragonal $P 4 \mathrm{~mm}$ symmetries. $Y_{\mathrm{Obs}}$ and $Y_{\mathrm{Cal}}$ refer to the measured and calculated intensities, respectively.

Table 2. Results of the Rietveld refinements of $\mathrm{Bi}_{0.62} \mathrm{~Pb}_{0.38} \mathrm{Fe}_{0.47} \mathrm{Mn}_{0.15} \mathrm{Ti}_{0.38} \mathrm{O}_{3}$ sample (composition 2), after (a) slow cooling and (b) quenching, using Pnma in the former, and coexistence of $C c$ and $P 4 \mathrm{~mm}$ in the latter. ${ }^{a}$

(a)

\begin{tabular}{ccccc}
\hline & $\mathrm{Bi} / \mathrm{Pb}$ & $\mathrm{Fe} / \mathrm{Mn} / \mathrm{Ti}$ & $\mathrm{O} 1$ & $\mathrm{O} 2$ \\
$x$ & $0.006(7)$ & 0 & $0.507(6)$ & $0.238(5)$ \\
$y$ & 0.25 & 0 & 0.25 & $0.003(6)$ \\
$z$ & $0.002(4)$ & 0.5 & $0.033(3)$ & $0.756(5)$ \\
$B_{\text {eq }}\left(\AA^{2}\right)$ & 2.66 & 0.67 & 1.50 & 1.50 \\
Lattice parameters $(\AA)$ & \multicolumn{4}{c}{$a=5.602(0) ; b=7.913(4) ; c=5.601(1)$} \\
Statistical parameters & $R_{\mathrm{wp}}=9.24 ; R_{\mathrm{P}}=8.11 ; R_{\exp }=6.65 ; R_{\text {Bragg }}=9.62 ; \mathrm{GOF}=1.39$
\end{tabular}

\begin{tabular}{|c|c|c|c|c|c|c|c|c|c|}
\hline \multirow[t]{2}{*}{ (b) } & \multicolumn{5}{|c|}{ Cc } & \multicolumn{4}{|c|}{$P 4 m m$} \\
\hline & $\mathrm{Bi} / \mathrm{Pb}$ & $\mathrm{Fe} / \mathrm{Mn} / \mathrm{Ti}$ & $\mathrm{O} 1$ & $\mathrm{O} 2$ & O3 & $\mathrm{Bi} / \mathrm{Pb}$ & $\mathrm{Fe} / \mathrm{Mn} / \mathrm{Ti}$ & $\mathrm{O} 1$ & $\mathrm{O} 2$ \\
\hline$x$ & 0 & $0.271(0)$ & $-0.015(2)$ & $0.335(9)$ & $0.300(6)$ & 0 & 0.5 & 0.5 & 0.5 \\
\hline$y$ & 0.25 & $0.246(0)$ & 0.25 & $0.456(6)$ & $0.037(9)$ & 0 & 0.5 & 0 & 0.5 \\
\hline Z & 0 & $0.726(0)$ & $0.559(7)$ & $0.060(0)$ & $-0.040(0)$ & 0 & $0.518(8)$ & $0.565(0)$ & $0.053(1)$ \\
\hline$B_{\text {eq }}\left(\AA^{2}\right)$ & 1.88 & 0.79 & 1.50 & 1.50 & 1.50 & 1.88 & 1.58 & 1.50 & 1.50 \\
\hline \multicolumn{3}{|c|}{ Lattice parameters $(\AA)$} & \multicolumn{3}{|c|}{$\begin{array}{c}a=9.773(7) ; \quad b=5.583(1) ; \\
c=5.615(4) ; \quad \beta=125.60(7)^{\circ}\end{array}$} & \multicolumn{4}{|c|}{$a=3.873(3) ; c=4.236(4)$} \\
\hline
\end{tabular}


Statistical parameters

Phase fraction

$$
\begin{gathered}
R_{\mathrm{wp}}=10.87 ; R_{\mathrm{p}}=9.38 ; R_{\exp }=6.75 ; R_{\mathrm{Bragg}}(C c)=15.65 ; R_{\mathrm{Bragg}}(P 4 \mathrm{~mm})=31.08 ; \mathrm{GOF}=1.61 \\
0.92(C c) / 0.08(P 4 \mathrm{~mm})
\end{gathered}
$$

${ }^{a}$ Position coordinates $(x, y, z)$, thermal parameters $\left(B_{\text {eq }}\right)$, reliability factors ( $R$-factors) and goodness-of-fit indicator (GOF) are given.

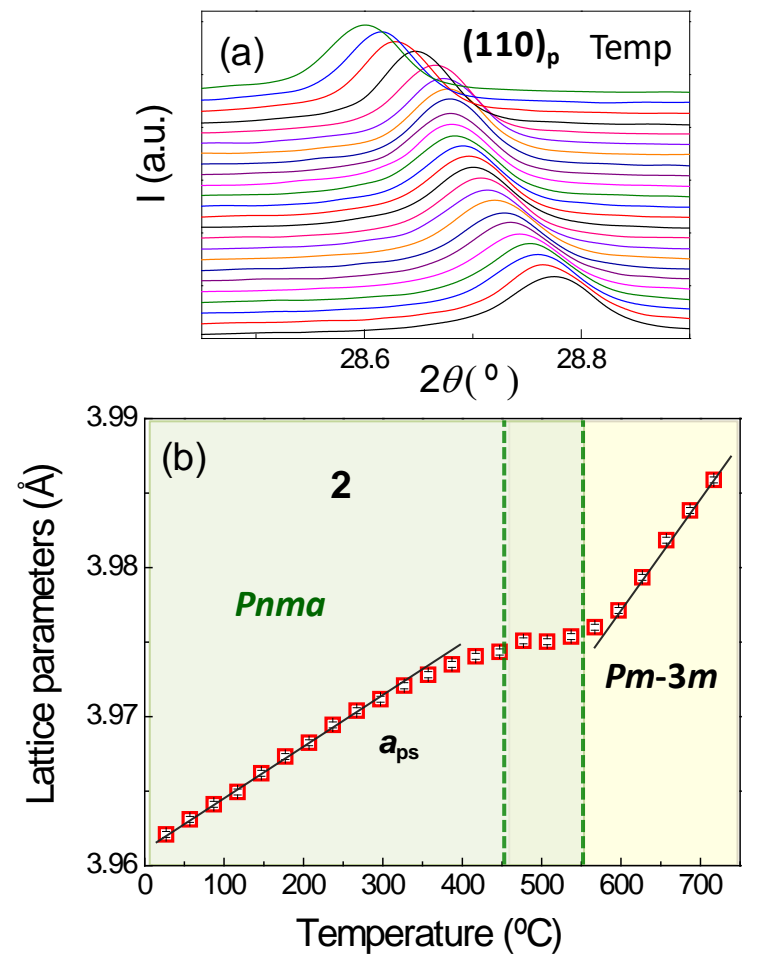

Figure 6. Temperature evolution of $\mathrm{XRD}$ profiles using $\mathrm{Cu} K_{\beta}$ around the $(110)_{\mathrm{p}}$ reflection (pseudocubic index) for powder sample of composition $2\left(\mathrm{Bi}_{0.62} \mathrm{~Pb}_{0.38} \mathrm{Fe}_{0.47} \mathrm{Mn}_{0.15} \mathrm{Ti}_{0.38} \mathrm{O}_{3}\right)$ after slow cooling. (b) Temperature evolution of the lattice parameter obtained from Le Bail analysis assuming to be pseudo-cubic $\left(a_{\mathrm{ps}}\right)$. Colored regions indicate different polymorphs.

3.2. Magnetic Properties. Figure 7 shows the temperature dependence of the molar magnetic susceptibility (M/H ratio) of powdered samples corresponding to compositions under study, after either slow cooling or quenching treatments, to establish the magnetic features of the different polymorphs. Let's first analyze the results for composition 4, which was structurally identified as monoclinic $C c$, and whose magnetic behavior indicates a weak spin-canted ferromagnetic component below 400 K [Fig. 7(a)]. No differences were found between slowly cooled and quenched samples in this case. The behavior is very similar to that reported for compositions at the MPB of the $\mathrm{BiFeO}_{3}-\mathrm{PbTiO}_{3}$ binary system, ${ }^{31}$ for which the anomaly was associated with a spin reorientation phenomenon within the AFM state. ${ }^{23}$ Indeed, a Néel temperature above $400 \mathrm{~K}$ has been reported for the $0.7 \mathrm{BiFeO}_{3}-0.3 \mathrm{PbTiO}_{3}$ (at $480 \mathrm{~K}$ ), ${ }^{37}$ a composi- tion close to that labeled 4 in this work. Below the SRO transition, $\mathrm{T}_{\mathrm{SRO}}$, the ferromagnetic component undergoes a spin flop, so that a larger net magnetic moment results. ${ }^{22}$ A weak ferromagnetic component would be highly desired to obtain a linear magnetoelectric effect, and indeed, it could be very useful in the search of room-temperature responses.

A similar magnetic behavior was obtained in the samples of compositions 1 and 2 after slow cooling and quenching treatments, respectively, in which the predominant polymorph is again the monoclinic $C c$ one. ZFC/FC curves again showed the SRO phenomenon and spin-canting ferromagnetism [Figs. 7(b) and 7(c)]. Note the shift of the SRO transition towards lower temperatures upon addition of $\mathrm{BiMnO}_{3}$ (that is, $\mathrm{T}_{\mathrm{SRO}}=222$ and $168 \mathrm{~K}$ for the compositions 1 and 2, respectively). Note also the small irreversibility of the ZFC/FC curves above the SRO transition that indicates the system to still present AFM ordering above it, and also beyond the measuring range. This seems to be the general picture of the magnetic behavior of monoclinic Cc phase within the ternary system under study.

A different behavior was found for the quenched material of composition 3 , in which the polymorph that largely prevails at room temperature is the tetragonal $\mathrm{P} 4 \mathrm{~mm}$ one. $\mathrm{ZFC} / \mathrm{FC}$ curves in this case showed mainly an overall near-paramagnetic behavior down to very low temperatures [Fig. 7(d)]. It should be noted that the small anomaly at $\sim 160 \mathrm{~K}$, along with the tiny irreversibility in the whole measuring range, are both rather related with the presence of a very small percentage of monoclinic phase than with the major tetragonal one. Indeed, we have recently shown that the anomaly corresponding to the AFM ordering of the tetragonal polymorph takes place at about $200 \mathrm{~K}$ for the $\mathrm{BiFeO}_{3}-\mathrm{PbTiO}_{3}$ binary system, ${ }^{16}$ but immediately shifted below $100 \mathrm{~K}$ upon adding a small amount of $\mathrm{BiMnO}_{3} .^{22}$ Therefore, a further shift to very low temperatures (see the small divergence about $2 \mathrm{~K}$ ), or even a vanishes, of the tetragonal AFM transition could be anticipated for the MPB compositions under study.

The magnetic behavior of these MPB compositions can then significantly differ depending on whether the material was quenched or slowly cooled from high temperature, a phenomenon that is closely related with the polymorph that results from the thermal treatment. This is the case of composition 2, for which ZFC/FC curves in the slowly cooled sample clearly indicated overall near-paramagnetic behavior down to very low temperatures [Fig. 7(e)], a material that was structurally identified as orthorhombic Pnma. Again, the small anomaly at 165 $\mathrm{K}$ and tiny irreversibility seem both to be related with the presence of traces of monoclinic phase. Indeed, this was the predominant magnetic feature of the quenched material [Fig. 7(c)]. 

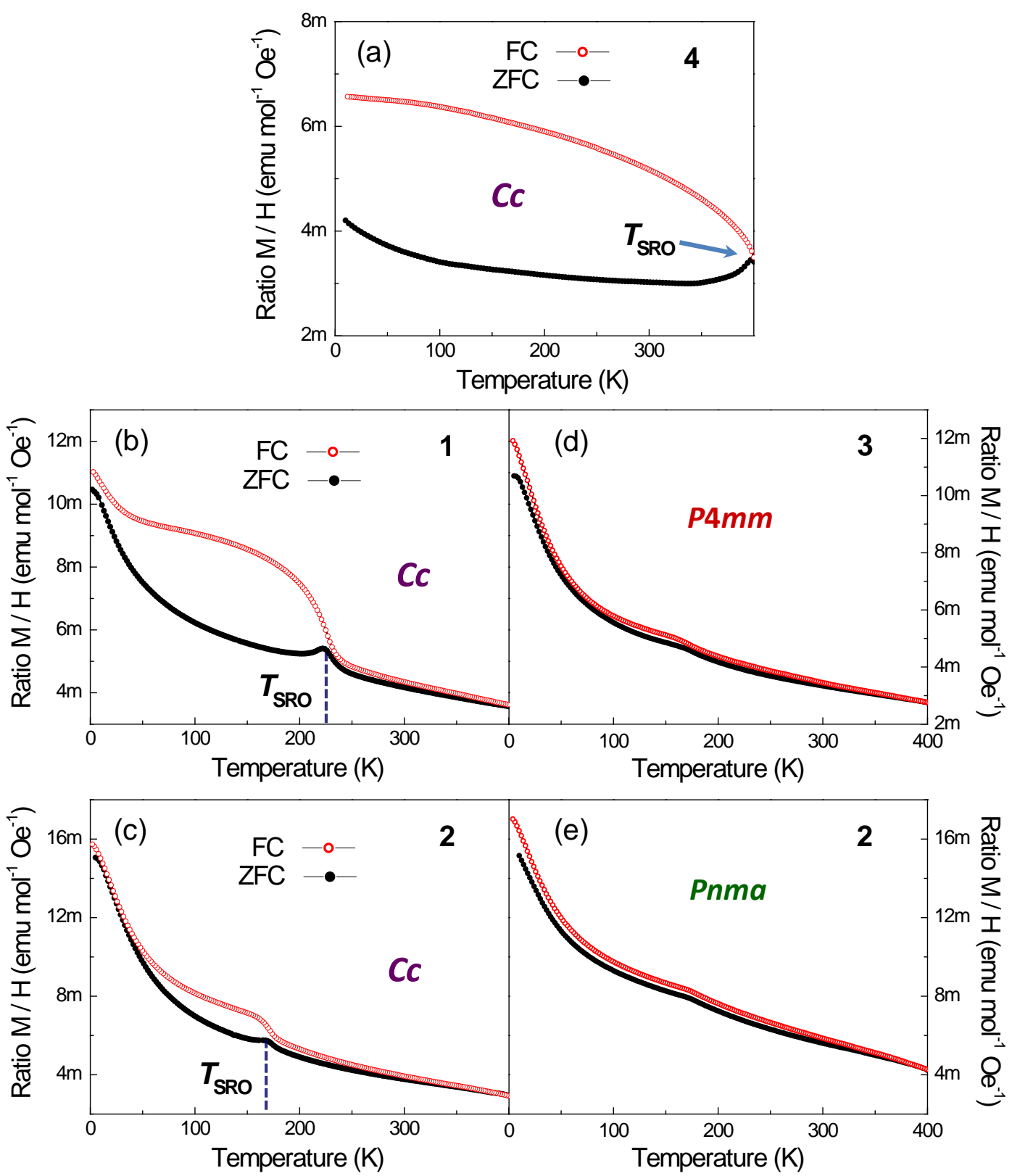

Figure 7. Zero-field-cooled/Field-cooled (ZFC/FC) susceptibility curves under a $d c$ magnetic field of 100 Oe for powder samples of composition (a) 4 - $\mathrm{Bi}_{0.75} \mathrm{~Pb}_{0.25} \mathrm{Fe}_{0.7} \mathrm{Mn}_{0.05} \mathrm{Ti}_{0.25} \mathrm{O}_{3}$, (b) 1 - $\mathrm{Bi}_{0.62} \mathrm{~Pb}_{0.38} \mathrm{Fe}_{0.52} \mathrm{Mn}_{0.1} \mathrm{Ti}_{0.38} \mathrm{O}_{3}$ slowly cooled, (c) 2 - $\mathrm{Bi}_{0.62} \mathrm{~Pb}_{0.38} \mathrm{Fe}_{0.47} \mathrm{Mn}_{0.15} \mathrm{Ti}_{0.38} \mathrm{O}_{3}$ with quenching, (d) $3-\mathrm{Bi}_{0.58} \mathrm{~Pb}_{0.42} \mathrm{Fe}_{0.47} \mathrm{Mn}_{0.11} \mathrm{Ti}_{0.42} \mathrm{O}_{3}$ with quenching and (e) 2 slowly cooled. Crystal structure is given for each case. TsRo indicates the magnetic anomaly associated with spin-reorientation phenomenon within the monoclinic $C c$ phase.

Results indicate that only the monoclinic phase presents AFM ordering and SRO phenomena close to room temperature, while magnetism vanishes for the tetragonal and orthorhombic polymorphs. This coexistence of polymorphs in the same material with a differentiated magnetism could be very useful for obtaining phase-change magnetoelectric responses.

The origin of this distinct magnetism among polymorphs deserves further discussion. On the one hand, both the AFM ordering and SRO phenomena associated to the monoclinic phase seem to be related with superexchange pathways on the $\mathrm{Fe}^{3+}$ sublattice. Addition of $\mathrm{BiMnO}_{3}$ increases chemical disorder, and gives rise to competing interactions between both the $\mathrm{Fe}$ and Mn magnetic species. This would explain the shift to lower temperature of the SRO anomaly of the monoclinic phase upon increasing $\mathrm{BiMnO}_{3}$. Moreover, defect chemistry and order/disorder features of this complex system need to be also considered. The role of manganese, which is known to readily adopt different oxidation states in perovskites, e.g. $\mathrm{Mn}^{3+}$ and $\mathrm{Mn}^{4+}$, after the formation of cation vacancies that are charge compensated by the mixed-valence state. ${ }^{36}$ Indeed, Pnma phase of the $\mathrm{BiMnO}_{3}-\mathrm{PbTiO}_{3}$ binary system, and its magnetic spin-glass behavior, have been associated with the presence of $\mathrm{Mn}^{4+} / \mathrm{Mn}^{3+}$ and the resulting competing interactions. ${ }^{26}$ The strong competition between superexchange of ferromagnetic $\left(\mathrm{Mn}^{4+}-\mathrm{O}-\mathrm{Mn}^{3+}\right)$ and negative AFM $\left(\mathrm{Mn}^{4+}-\mathrm{O}-\mathrm{Mn}^{4+}\right.$ and $\left.\mathrm{Mn}^{3+}-\mathrm{O}-\mathrm{Mn}^{3+}\right)$ interactions lead to freezing of the local magnetic moment and spinclustering with random orientations. ${ }^{38}$ This would explain the 
absence of long-range order in both P4mm and Pnma phases within this ternary system.

3.3. Dielectric Properties. Figure 8 shows the temperature dependences of the relative permittivity $\left(K^{\prime}\right)$ and dielectric losses $\left(\tan \delta\right.$ ) of ceramics processed at $950{ }^{\circ} \mathrm{C}$, corresponding to the different compositions under study. Dielectric curves at several frequencies during heating stage are given in Fig. 8(a) for sample of composition 1 , taken by way of example. Similar frequency dependence of the dielectric behavior was found for all compositions. Note the Maxwell-Wagner relaxation below 400 ${ }^{\circ} \mathrm{C}$, that is, a step-like increase in $\mathrm{K}^{\prime}$ at a temperature that shifts with frequency, a phenomenon usually associated with the presence of significant electrical conductivity in these materials. ${ }^{39}$ This is also evident in $\tan \delta$ curves, directly proportional to conductivity, in which large frequency dispersion and high losses were obtained. The anomaly associated with the transition from the ferroelectric to paraelectric phase is observed at $T_{C}=575$ ${ }^{\circ} \mathrm{C}$ for this composition in ceramic form, which is expected to be monoclinic Cc. A cooling rate of $3{ }^{\circ} \mathrm{C} \mathrm{min}^{-1}$ was used during the hot pressing, so room temperature phases should be those described for slowly cooled powders. XRD patterns of ceramics are consistent with this hypothesis, though they showed an increased broadening associated with the lower crystallinity and the ceramic stress field that hinders phase determination.

Figure 8(b) shows the dielectric curves during a heating/ cooling cycle at $1 \mathrm{MHz}$ for compositions 1, 2 and 4 (high-frequency data is given to minimize conduction contributions). The dielectric anomaly associated with the ferroelectric transition shifted to lower temperatures, in both permittivity and losses, with increasing the amount of $\mathrm{Mn}$ in these materials (that is, $4 \rightarrow 1 \rightarrow 2$ ), along with a decrease of maximum permittivity, which is consistent with previous works. ${ }^{31}$ All dielectric curves showed the typical hysteresis on a heating/cooling cycle for a first-order ferroic transition, like those obtained in $\mathrm{BiFeO}_{3}$-rich compositions of the $\mathrm{BiFeO}_{3}-\mathrm{PbTiO}_{3}$ binary system. ${ }^{14}$ Samples of compositions 4 and 1 were monoclinic $C c$ after a slow cooling, and thus, a ferroelectric transition takes place in this case. However, powders of composition 2 were clearly Pnma and this polymorph was recently claimed as antiferroelectric. ${ }^{26}$ The presence of a dielectric anomaly supports this assertion and thus, a transition from antiferroelectric to paraelectric seems to take place for this specific material.
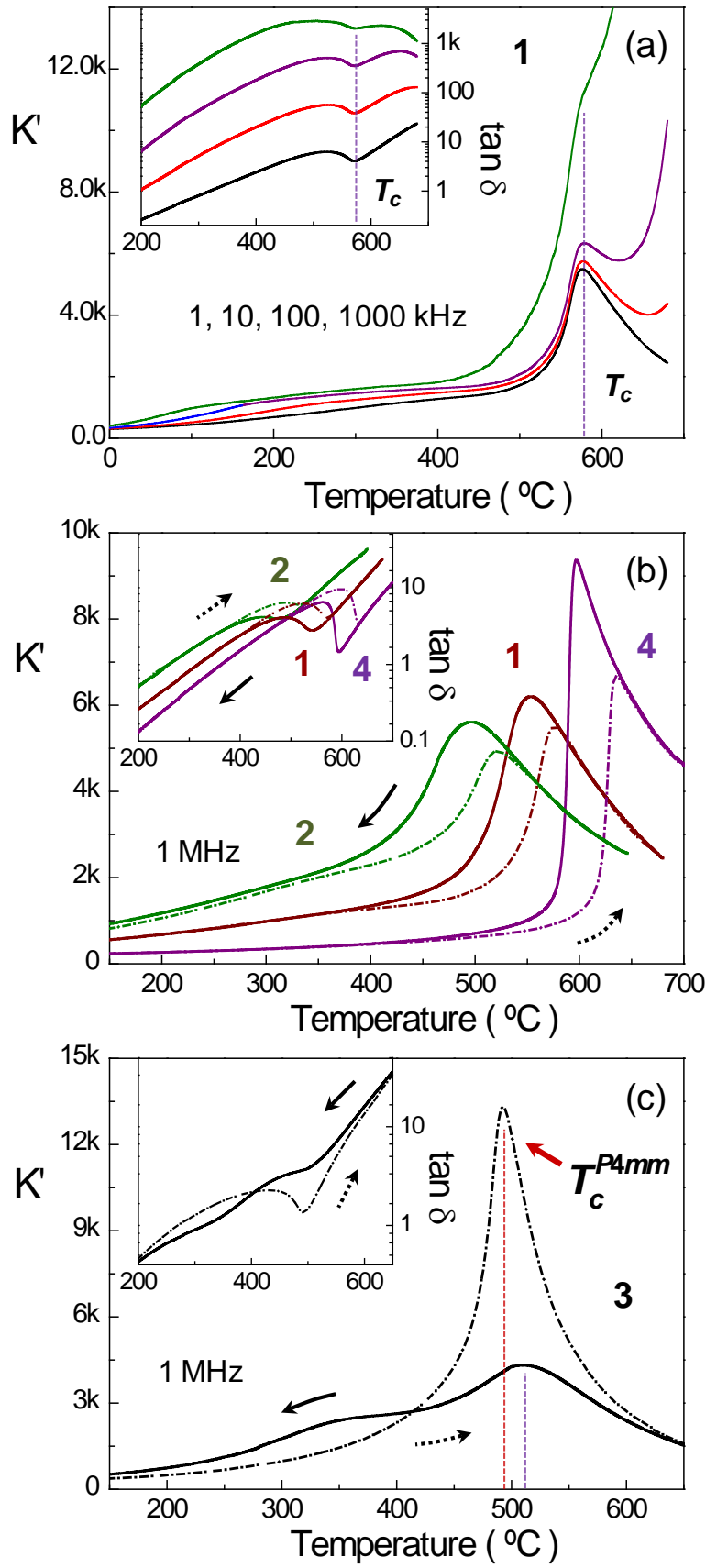

Figure 8. Temperature dependences of the relative permittivity (K') and (inset) dielectric losses (tan $\delta$ ) of ceramics corresponding to different compositions. (a) Curves at several frequencies during heating for composition 1 (arrows indicate increasing frequency, $\mathrm{T}_{\mathrm{C}}$ - Curie temperature). (b,c) Curves at $1 \mathrm{MHz}$ during a heating/ cooling cycle for compositions: 1 $\mathrm{Bi}_{0.62} \mathrm{~Pb}_{0.38} \mathrm{Fe}_{0.52} \mathrm{Mn}_{0.1} \mathrm{Ti}_{0.38} \mathrm{O}_{3}$, 2

$\mathrm{Bi}_{0.62} \mathrm{~Pb}_{0.38} \mathrm{Fe}_{0.47} \mathrm{Mn}_{0.15} \mathrm{Ti}_{0.38} \mathrm{O}_{3}$ with quenching, $3-\mathrm{Bi}_{0.58} \mathrm{~Pb}_{0.42}$ $\mathrm{Fe}_{0.47} \mathrm{Mn}_{0.11} \mathrm{Ti}_{0.42} \mathrm{O}_{3}$, and $4-\mathrm{Bi}_{0.75} \mathrm{~Pb}_{0.25} \mathrm{Fe}_{0.7} \mathrm{Mn}_{0.05} \mathrm{Ti}_{0.25} \mathrm{O}_{3}$.

Transition temperatures of 520 and $495{ }^{\circ} \mathrm{C}$ were obtained from the dielectric curves on heating and cooling, respectively. This is in agreement with the temperature range at which a transition from Pnma to Pm-3m symmetries was described from the temperature evolution of the XRD profiles of slowly cooled powders [Fig. 6(b)]. Note the large difference in $T_{C}$ found be- 
tween the heating and cooling runs $\left(\Delta \mathrm{T}_{\mathrm{C}} \sim 35\right.$ to $\left.25^{\circ} \mathrm{C}\right)$, an effect characteristic of materials at MPBs, and that has also been related to different sequences of polymorphic phase transitions during heating and cooling runs. ${ }^{14,22}$ Indeed, related effects have been clearly identified in quenched ceramics, as it is illustrated for composition 3 in Fig. 8(c). Recall that a tetragonal phase had been obtained for quenched powders of this composition [Fig. 3(c)]. It is remarkable the highly irreversible character of the transition during a first thermal cycle, with a maximum relative permittivity in excess of 12000 at $\mathrm{T}_{\mathrm{C}}$ of $\sim 490{ }^{\circ} \mathrm{C}$ on heating, that is, three times greater than that on cooling at $\sim 510^{\circ} \mathrm{C}$.

Thermal hysteresis of a first-order ferroic transition is always such that $\mathrm{T}_{\mathrm{C}}$ on cooling is lower than that on heating. Therefore, results obtained can only be associated to a different sequence of polymorphic transitions, specifically from the $P 4 \mathrm{~mm}$ phase on heating, which is the polymorph favored by quenching, and to the $C c$ phase on cooling (according to the XRD characterization of slowly cooled powders). Also remarkable it is the enhancement of polarizability at $\mathrm{T}_{\mathrm{C}}$ in the quenched material, related with the presence of the tetragonal polymorph, as compared to that of the monoclinic phase.

Differences in room temperature phases between samples either slowly cooled or quenched from high temperature have been associated with the key presence of $\mathrm{Mn}$, and the related defect chemistry of these oxides, ${ }^{26}$ which is usually dominated by $A$-site and oxygen vacancies along with reduction/oxidation of the magnetic species at the $B$-site. ${ }^{36,40}$ One can expect the equilibrium oxygen content at high temperature to be frozen at room temperature by quenching, favoring the tetragonal distortion. A slow cooling, however, provides more time for equilibration of the oxygen, involving variations in the oxidation state of cations at $B$-sites ( $\mathrm{Mn}$ and $\mathrm{Fe}$ ), thus resulting in changes in the tolerance factor and pushing the system across the MPB. Specifically, the antipolar orthorhombic Pnma, which is one of the most common space groups in perovskite oxides, ${ }^{41}$ has been related to the presence of $\mathrm{Mn}^{4+}$ and the resulting decreased distortions that it produces, favoring the centrosymmetric structure. ${ }^{26,36}$ Note from the schematic phase diagram shown in Fig. 1 , that the whole solid solution between $\mathrm{BiFeO}_{3}$ and $\mathrm{PbTiO}_{3}$ is polar and ferroelectric, with either $P 4 m m, C c$ or $R 3 c$ symmetry. It is the Mn incorporation which results in MPB regions with the antipolar Pnma phase, not only in both binary systems but also in the ternary one.

The role of the oxygen content, and its equilibration kinetics, was confirmed in a series of ceramics of composition 1, with quenching from increasing temperatures. Figure 9(a) shows the temperature dependence of relative permittivity during heating at $1 \mathrm{MHz}$ for the different samples. Only one dielectric anomaly was obtained (at $575^{\circ} \mathrm{C}$ ) in the slowly cooled sample, which must correspond to the ferroelectric to paraelectric transition of the monoclinic polymorph, the one prevailing in this ceramic sample. In the quenched materials, however, a second anomaly appears at $\sim 520^{\circ} \mathrm{C}$ with increasing the quenching temperature, which largely dominates the dielectric response after quenching at $900{ }^{\circ} \mathrm{C}$. This latter anomaly is very similar to that of composition 3 after quenching, as shown in Fig. 8(c). Note again the huge permittivity in excess of 20000 at $\mathrm{T}_{\mathrm{C}}$, that is, five times greater than that after slow cooling. The anomaly at $520^{\circ} \mathrm{C}$ thus corresponds to the ferroelectric transition of the tetragonal polymorph to the paraelectric cubic one. Note that the two anomalies can be distinguished in the curve of the ceramic quenched from $800^{\circ} \mathrm{C}$, which is likely related to an intermediate situation.
In this case, the oxygen equilibrium at high temperature would only be achieved in the grain shell, so that a reduced shell, then most probably tetragonal, would be formed around a still oxidized core, which is so monoclinic, after the quenching.

Finally, a distinctive grain size effect on the ferroelectric transition was found in ceramics of composition 1, processed at decreasing temperatures. A very similar effect to that found by quenching was obtained when grain size was reduced across the submicron range down to the nanoscale, as shown in Fig. 9(b). Average grain sizes varied between $0.82 \mu \mathrm{m}$ and $70 \mathrm{~nm}$ in this set of ceramics (Fig. 2). Samples sintered at 1000 and $900{ }^{\circ} \mathrm{C}$, with grain sizes in the submicron range, showed a single dielectric anomaly at $575{ }^{\circ} \mathrm{C}$, which was related above with the ferroelectric transition of the monoclinic phase, the one prevailing in this material according to XRD. Grain size effect in these two samples was basically a decrease of the maximum
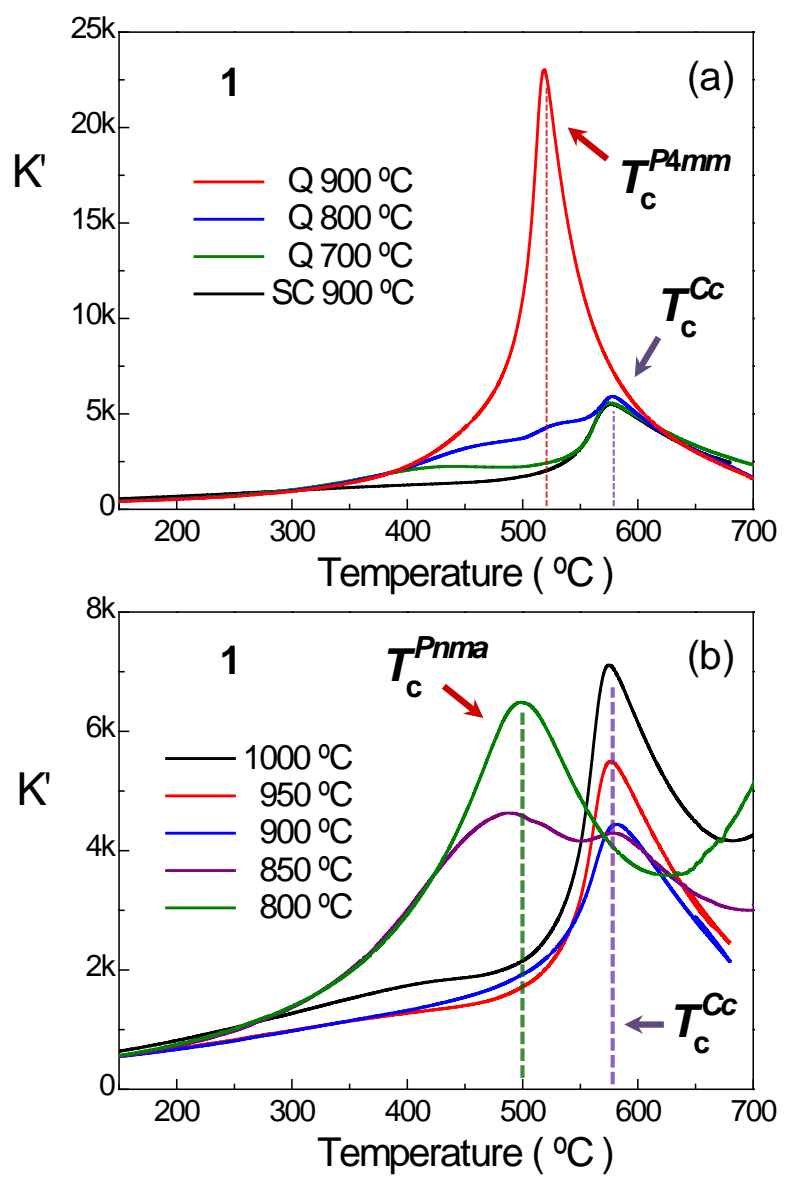

Figure 9. Temperature dependences of the relative permittivity $\left(\mathrm{K}^{\prime}\right)$ at $1 \mathrm{MHz}$ during heating for ceramics of composition 1 $\left(\mathrm{Bi}_{0.62} \mathrm{~Pb}_{0.38} \mathrm{Fe}_{0.52} \mathrm{Mn}_{0.1} \mathrm{Ti}_{0.38} \mathrm{O}_{3}\right)$. (a) Samples after thermal treatment at $900^{\circ} \mathrm{C}$ with slow cooling (SC $900^{\circ} \mathrm{C}$ ) or quenching from increasing temperatures (Q700 ${ }^{\circ} \mathrm{C}, 800{ }^{\circ} \mathrm{C}, 900{ }^{\circ} \mathrm{C}$ ). (b) Samples obtained at different hot-pressing temperatures (dashed lines and $\mathrm{T}_{\mathrm{C}}$ are Curie temperatures).

permittivity, while no change in $\mathrm{T}_{\mathrm{C}}$ was observed. However, the ceramic sintered at $850{ }^{\circ} \mathrm{C}$, with a grain size approaching the nanoscale, showed a new dielectric anomaly at a temperature below $500{ }^{\circ} \mathrm{C}$, while that associated with the monoclinic to cubic transition is still present at $575^{\circ} \mathrm{C}$. Moreover, and in the nanostructured ceramic (the one sintered at $800{ }^{\circ} \mathrm{C}$ ), the latter transition is no longer observed and only one anomaly appears 
at $\sim 500{ }^{\circ} \mathrm{C}$. These results seem to suggest that tetragonal polymorph is the one stabilized in the nanoscale, just like quenching treatments do. However, this apparent analogy must be handled with care, because oxygen equilibration should be favored by size decrease and thus, one would expect the monoclinic phase to be promoted. Alternative mechanisms need to be considered.

Grain size effects on the functional properties of ferroelectric materials, and in particular those with MPB, have been extensively studied, and an understanding of the mechanisms that rule these size effects has been built. ${ }^{42-44}$ The most noticeable effect of decreasing the grain size into the submicron range, and further down to the nanoscale, on the dielectric properties of ferroelectric ceramics is the progressive broadening and depletion of the maximum in permittivity at the phase transition. A combination of grain size and grain boundary effects has been proposed, like the disappearance of the complex domain configurations present in coarse-grained ceramics at the nanoscale, ${ }^{45}$ along with the increasing contribution to the dielectric response of the large volume fractions of grain boundaries with strongly reduced permittivity. ${ }^{43}$

Grain boundary effects could be behind the decrease in permittivity at the monoclinic to cubic transition with reducing grain sizes in the submicron range (samples sintered at 1000 and $900{ }^{\circ} \mathrm{C}$ ). However, the new anomaly emerging at $500{ }^{\circ} \mathrm{C}$ for nanostructured samples must have a different origin. As mentioned above, this seems to correspond to a different polymorph that might be either tetragonal or orthorhombic, which are the other two phases involved in this region where two MPBs meet (see Fig. 1). We have argued that a tetragonal polymorph would not be expected from oxygen equilibration arguments. Besides, general trend in tetragonal perovskites is the final disappearance of the tetragonal distortion with the size decrease, once ferroelastic domains are not formed at the nanoscale. ${ }^{45,46}$ Therefore, the antipolar Pnma phase seems to be the stabilized phase. This might be the consequence of a more complete sample oxidation as a result of the decreased diffusion distances, so that a sequence of P4mm, Cc and Pnma would take place in this composition when increasing levels of $\mathrm{Mn}^{4+}$ are introduced. Actually, a monoclinic to orthorhombic transition can be promoted in $\mathrm{BiMnO}_{3+\delta}$ by increasing $\delta .{ }^{47}$ However, a true intrinsic size effect cannot be ruled out.

\section{CONCLUSIONS}

We have prepared a number of compositions belonging to the $\mathrm{BiFeO}_{3}-\mathrm{BiMnO}_{3}-\mathrm{PbTiO}_{3}$ ternary system at or next to a line of $\mathrm{MPBs}$, in the region where the evolution from $P 4 \mathrm{~mm} / \mathrm{Cc}$-type

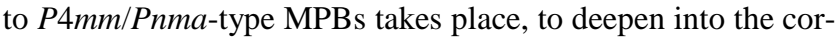
relations among the crystal structure, defect chemistry and physical properties of the three polymorphs involved in phase coexistence within this region. High-resolution XRD diffraction allowed establishing the actual symmetry of the phases coexisting at the MPB, namely monoclinic Cc, tetragonal $P 4 m m$ and orthorhombic Pnma, so that up to three polymorphs might be present in the same material. Strong thermal history effects in the phase coexistence were found, so percentages of coexisting phases significantly change whether the material is quenched or slowly cooled from high temperature. The origin of this behavior is related with the defect chemistry and the role of mixed-valence states at $B$-sites.

The overall magnetic behavior differs significantly for samples with the different thermal treatments, allowing establishing the type of magnetic interactions for each polymorphic phase.
A weak ferromagnetic moment was found at room temperature within the $C c$ phase, which is also ferroelectrics and allows lattice transverse softening. Linear magnetoelectric responses can be expected in this phase. On the contrary, near-paramagnetic behavior down to very low temperatures was found for the P4mm and Pnma polymorphs, whereas the former was ferroelectric (and highly polarizable) and the latter antiferroelectric (and so antipolar by nature). Large phase-change magnetoelectric responses can be then anticipated in this region as a result of field-induced phase transitions. Besides, high-quality ceramic materials with tailored microstructures, and average grain sizes across the submicron range and approaching the nanoscale, were processed by hot-pressing of nanocrystalline powders obtained by mechanosynthesis, which enabled additionally addressing size effects. Distinctive effects of grain size on the transition sequence, and thus on the phase stabilized at room temperature, were found when size was reduced down to the nanoscale. This provides an additional degree of freedom to tailor phase coexistence, and so to obtain controlled percentages of polymorphic phases with differentiated magnetism and ferroelectricity in the same material for enhanced phase-change magnetoelectric responses.

\section{AUTHOR INFORMATION}

\section{Corresponding Author}

*(H.A.) E-mail: hamorin@icmm.csic.es

ORCID

Carmen M. Fernández-Posada: 0000-0003-3080-1637

Harvey Amorín: 0000-0001-9915-1631

\section{Present Addresses}

‡ Department of Earth Sciences, University of Cambridge, Downing Street, Cambridge CB2 3EQ, UK.

\section{Notes}

The authors declare no competing financial interest.

\section{ACKNOWLEDGMENT}

Funded by Spanish MINECO through projects MAT2014-58816$\mathrm{R}$ and MAT2017-88788-R. Technical support by Ms. Inma Martínez (ICMM-CSIC) is gratefully acknowledged.

\section{ABBREVIATIONS}

MPB, morphotropic phase boundary; AFM, antiferromagnetic; $\mathrm{SRO}$, spin reorientation.

\section{REFERENCES}

(1) Spaldin, N. A.; Fiebig, M. The Renaissance of Magnetoelectric Multiferroics. Science 2005, 309, 391-392.

(2) Eerenstein, W.; Mathur, N. D.; Scott, J. F. Multiferroic and Magnetoelectric Materials. Nature 2006, 442, 759-765.

(3) Spaldin, N. A.; Cheong, S. W.; Ramesh, R. Multiferroics: Past, Present, and Future. Phys. Todav 2010, 63, 38-43.

(4) Fiebig, M. Revival of the Magnetoelectric Effect. J. Phys. D: Appl. Phys. 2005, 38, R123-R152.

(5) Bibes, M.; Barthelemy, A. Multiferroics: Towards a Magnetoelectric Memory. Nat. Mater. 2008, 7, 425-426.

(6) Scott, J. F. Applications of Magnetoelectrics. J. Mater. Chem. 2012, 22, 4567-4574.

(7) Wang, Y.; Li, J.; Viehland, D. Magnetoelectrics for Magnetic Sensor Applications: Status, Challenges and Perspectives. Mater. Today 2014, 17, 269-275. 
(8) Bersuker, I. B. Pseudo Jahn-Teller Origin of Perovskite Multiferroics, Magnetic-Ferroelectric Crossover, and Magnetoelectric Effects: The $\mathrm{d}^{0}-\mathrm{d}^{10}$ Problem. Phys. Rev. Lett. 2012, 108, 137202.

(9) Belik, A. A. Polar and Nonpolar Phases of $\mathrm{BiMO}_{3}$ : A Review. J. Solid State Chem. 2012, 195, 32-40.

(10) Wu, J.; Fan, Z; Xiao, D.; Zhu, J.; Wang J. Multiferroic Bismuth Ferrite-based Materials for Multifunctional Applications: Ceramic Bulks, Thin Films and Nanostructures. Prog. Mater. Sci. 2016, 84, 335402.

(11) Choi, E.-M.; Fix, T.; Kursumovic, A.; Kinane, C. J.; Arena, D.; Sahonta, S.-L.; Bi, Z.; Xiong, J.; Yan, L.; Lee, J.-S.; et al. Room Temperature Ferrimagnetism and Ferroelectricity in Strained, Thin Films of $\mathrm{BiFe}_{0.5} \mathrm{Mn}_{0.5} \mathrm{O}_{3}$. Adv. Funct. Mater. 2014, 24, 7478-7487.

(12) Modak, P.; Lahiri, D.; Sharma, S. M. Correlation Between Structure and Ferromagnetism in Nano-BiFeO 3. J. Phys. Chem. C 2016, 120, 8411-8416.

(13) Hungría, T.; Correas, C.; Houdellier, F.; Peña, O.; Vila, E.; Castro, A. Study of Nanocrystalline $\mathrm{BiMnO}_{3}-\mathrm{PbTiO}_{3}$ : Synthesis, Structural Elucidation, and Magnetic Characterization of the Whole Solid Solution. Chem. Eur. J. 2012, 18, 9075-9082.

(14) Amorín, H.; Correas, C.; Fernandez-Posada, C. M.; Peña, O.; Castro, A.; Algueró, M. Multiferroism and Enhancement of Materials Properties Across the Morphotropic Phase Boundary of $\mathrm{BiFeO}_{3}-$ $\mathrm{PbTiO}_{3}$. J. Appl. Phvs. 2014, 115, 104104.

(15) Mandal, P.; Pitcher, M. J.; Alaria, J.; Niu, H.; Borisov, P.; Stamenov, P.; Claridge J. B.; Rosseinsky, M. J. Designing Switchable Polarization and Magnetization at Room Temperature in an Oxide. Nature 2015, 525, 363-366.

(16) Amorín, H.; Correas, C.; Ramos, P.; Hungría, T.; Castro, A.; Algueró, M. Very High Remnant Polarization and Phase-Change Electromechanical Response of $\mathrm{BiFeO}_{3}-\mathrm{PbTiO}_{3}$ at the Multiferroic Morphotropic Phase Boundary. Appl. Phys. Lett. 2012, 101, 172908.

(17) Diéguez, O.; Iñiguez, J. First-Principles Investigation of Morphotropic Transitions and Phase-Change Functional Responses in $\mathrm{BiFeO}_{3}-\mathrm{BiCoO}_{3}$ Multiferroic Solid Solutions. Phys. Rev. Lett. 2011, $107,057601$.

(18) Hojo, H.; Oka, K.; Shimizu, K.; Yamamoto, H.; Kawabe, R.; Azuma, M. Development of Bismuth Ferrite as a Piezoelectric and Multiferroic Material by Cobalt Substitution. Adv. Mater. 2018, 30, 1705665.

(19) Xu, B.; Wang, D.; Íñiguez, J.; Bellaiche, L. Finite-Temperature Properties of Rare-Earth-Substituted $\mathrm{BiFeO}_{3}$ Multiferroic Solid Solutions. Adv. Funct. Mater. 2015, 25, 552-558.

(20) Knee, C. S.; Tucker, M. G.; Manuel, P.; Cai, S.; Bielecki, J.; Börjesson, L.; Eriksson, S. G. High Pressure Crystal and Magnetic Phase Transitions in Multiferroic $\mathrm{Bi}_{0.9} \mathrm{La}_{0.1} \mathrm{FeO}_{3}$. Chem. Mater. 2014, 26, 1180-1186.

(21) Kan, D.; Pálová, L.; Anbusathaiah, V.; Cheng, C. J.; Fujino, S.; Nagarajan, V.; Rabe, K. M.; Takeuchi, I. Universal Behavior and Electric-Field-Induced Structural Transition in Rare-Earth-Substituted $\mathrm{BiFeO}_{3}$. Adv. Funct. Mater. 2010, 20, 1108-1115.

(22) Fernandez-Posada, C. M.; Castro, A.; Kiat, J. M.; Porcher, F.; Peña, O.; Algueró, M.; Amorín, H. A Novel Perovskite Oxide Chemically Designed to Show Multiferroic Phase Boundary with Room-Temperature Magnetoelectricity. Nat. Commun. 2016, 7, 12772.

(23) Bhattacharjee, S.; Senyshyn, A.; Fuess, H.; Pandey, D. MorinType Spin Reorientation Transition below the Néel Transition in the Monoclinic Compositions of $(1-x) \mathrm{BiFeO}_{3}-x \mathrm{PbTiO}_{3}(x=0.25$ and 0.27): A Combined dc Magnetization and X-Ray and Neutron Powder Diffraction Study. Phys. Rev. B 2013, 87, 054417.

(24) Guo, R.; Cross, L. E.; Park, S. E.; Noheda, B.; Cox, D. E.; Shirane, G. Origin of the High Piezoelectric Response in $\mathrm{PbZr}_{1-x} \mathrm{Ti}_{x} \mathrm{O}_{3}$. Phys. Rev. Lett. 2000, 84, 5423-5426.

(25) Wojdel, J. C.; Iñiguez, J. Ab Initio Indications for Giant Magnetoelectric Effects Driven by Structural Softness. Phys. Rev. Lett. 2010, 105, 037208.

(26) Fernandez-Posada, C. M.; Castro, A.; Kiat, J. M.; Porcher, F.; Peña, O.; Jiménez, R.; Algueró, M.; Amorín, H. The Polar/Antipolar Phase Boundary of $\mathrm{BiMnO}_{3}-\mathrm{BiFeO}_{3}-\mathrm{PbTiO}_{3}$ : Interplay Among Crystal Structure, Point Defects, and Multiferroism. Adv. Funct. Mater. 2018, 28, 1802338.
(27) Mulder, A. T.; Benedek, N. A.; Rondinelli, J. M.; Fennie, C. J. Turning $\mathrm{ABO}_{3}$ Antiferroelectrics Into Ferroelectrics: Design Rules for Practical Rotation-driven Ferroelectricity in Double Perovskites and $\mathrm{A}_{3} \mathrm{~B}_{2} \mathrm{O}_{7}$ Ruddlesden-Popper Compounds. Adv. Funct. Mater. 2013, 23, 4810-4820.

(28) Bhattacharjee, S.; Pandey, D. Stability of the Various Crystallographic Phases of the Multiferroic $(1-x) \mathrm{BiFeO}_{3}-x \mathrm{PbTiO}_{3}$ System as a Function of Composition and Temperature. J. Appl. Phys. 2010, 107, 124112.

(29) Kirsch, A.; Murshed, M. M.; Kirkham, M. J.; Huq, A.; Litterst, F. J.; Gesing, T. M. Temperature-dependent Structural and Spectroscopic Studies of $\left(\mathrm{Bi}_{1-x} \mathrm{Fe}_{x}\right) \mathrm{FeO}_{3}$. J. Phvs. Chem. C 2018, 122, 2828028291.

(30) Wei, J.; Wu, C.; Yang, T.; Lv, Z.; Xu, Z.; Wang, D.; Haumont, R.; Cheng, Z. Temperature-Driven Multiferroic Phase Transitions and Structural Instability Evolution in Lanthanum-Substituted Bismuth Ferrite. J. Phys. Chem. C 2019, 123, 4457-4468.

(31) Fernandez-Posada, M.; Amorín, H.; Correas, C.; Peña, O.; Algueró, M.; Castro, A. Mechanosynthesis and Multiferroic Properties of the $\mathrm{BiFeO}_{3}-\mathrm{BiMnO}_{3}-\mathrm{PbTiO}_{3}$ Ternary System Along the Morphotropic Phase Boundary. J. Mater. Chem. C 2015, 3, 2255-2265.

(32) Petricek, V.; Dusek, M.; Palatinus, L. Crystallographic Computing System JANA2006: General Features. Z. Kristallogr. 2014, 229, 345-352.

(33) Castro, A.; Correas, C.; Peña, O.; Landa-Canovas, A. R.; Algueró, M.; Amorín, H.; Dolle, M.; Vila, E.; Hungría, T. Nanostructured $\mathrm{BiMnO}_{3+\delta}$ Obtained at Ambient Pressure: Analysis of Its Multiferroicity. J. Mater. Chem. 2012, 22, 9928-9938.

(34) Howard, C. J.; Stokes, H. T. Structures and Phase Transitions in Perovskites - A Group-Theoretical Approach. Acta Crystallogr. Sect. A 2005, 61, 93-111.

(35) Grande, T.; Tolchard, J. R.; Selbach, S. M. Anisotropic Thermal and Chemical Expansion in Sr-Substituted $\mathrm{LaMnO}_{3+\delta}$ : Implications for Chemical Strain Relaxation. Chem. Mater. 2012, 24, 338-345.

(36) Selbach, S. M.; Tybell, T.; Einarsrud, M. A.; Grande, T. Structure and Properties of Multiferroic Oxygen Hyperstoichiometric $\mathrm{BiFe}_{1-}$ ${ }_{x} \mathrm{Mn}_{x} \mathrm{O}_{3+\delta}$. Chem. Mater. 2009, 21, 5176-5186.

(37) Zhu, W. M.; Guo, H. Y.; Ye, Z. G. Structural and Magnetic Characterization of Multiferroic $\left(\mathrm{BiFeO}_{3}\right)_{1-x}\left(\mathrm{PbTiO}_{3}\right)_{x}$ Solid Solutions. Phys. Rev. B 2008, 78, 014401.

(38) Knobel, M.; Nunes, W. C.; Socolovsky, L. M.; De Biasi, E.; Vargas, J. M.; Denardin, J. C. Superparamagnetism and Other Magnetic Features in Granular Materials: A Review on Ideal and Real Systems. J. Nanosci. Nanotechnol. 2008, 8, 2836-2857.

(39) Rojac, T.; Bencan, A.; Malic, B.; Tutuncu, G.; Jones, J. L.; Daniels, J. E. $\mathrm{BiFeO}_{3}$ Ceramics: Processing, Electrical, and Electromechanical Properties. J. Am. Ceram. Soc. 2014, 97, 1993-2011.

(40) Geneste, G.; Paillard, C.; Dkhil, B. Polarons, Vacancies, Vacancy Associations, and Defect States in Multiferroic $\mathrm{BiFeO}_{3}$. Phys. Rev. B 2019, 99, 024104.

(41) Granger, P.; Parvulescu, V. I.; Kaliaguine, S.; Prellier, W. Perovskites and Related Mixed Oxides: Concepts and Applications; WileyVCH: Weinheim, Germany, 2015.

(42) Algueró, M.; Amorín, H.; Hungría, T.; Galy, J.; Castro, A. Macroscopic Ferroelectricity and Piezoelectricity in Nanostructured BiS$\mathrm{cO}_{3}-\mathrm{PbTiO}_{3}$ Ceramics. Appl. Phys. Lett. 2009, 94, 012902.

(43) Amorín, H.; Jiménez, R.; Deluca, M.; Ricote, J.; Hungría, T.; Castro, A.; Algueró, M. Nanostructuring Effects in Piezoelectric BiS$\mathrm{CO}_{3}-\mathrm{PbTiO}_{3}$ Ceramics. J. Am. Ceram. Soc. 2014, 97, 2802-2809.

(44) Amorín, H.; Algueró, M.; Del Campo, R.; Vila, E.; Ramos, P.; Dolle, M.; Romaguera-Barcelay, Y.; Pérez-De la Cruz, J.; Castro, A. High-Sensitivity Piezoelectric Perovskites for Magnetoelectric Composites. Sci. Technol. Adv. Mater. 2015, 16, 016001.

(45) Narayan, B.; Sorb, Y. A.; Loukya, B.; Samanta, A.; Senyshyn, A.; Datta, R.; Singh, A. K.; Narayana, C.; Ranjan, R. Interferroelectric Transition as Another Manifestation of Intrinsic Size Effect in Ferroelectrics. Phys. Rev. B 2016, 94, 104104.

(46) Amorín, H.; Ricote, J.; San-Felipe, I.; Salazar, N.; del Campo, R.; Romaguera-Barcelay, Y.; Pérez de la Cruz, J.; Ramos, P.; Vila, E.; Castro, A.; et al. Multilayer Ceramic Magnetoelectric Composites with 
Tailored Interfaces for Enhanced Response. ACS Appl. Mater. Interfaces 2017, 9, 39094-39104.
(47) Belik, A. A.; Kodama, K.; Igawa, N.; Shamoto, S.; Kosuda K.; Takayama-Muromachi, E. Crystal and Magnetic Structures and Properties of $\mathrm{BiMnO}_{3+\delta}$. J. Am. Chem. Soc. 2010, 132, 8137-8144. 
TOC Graphic

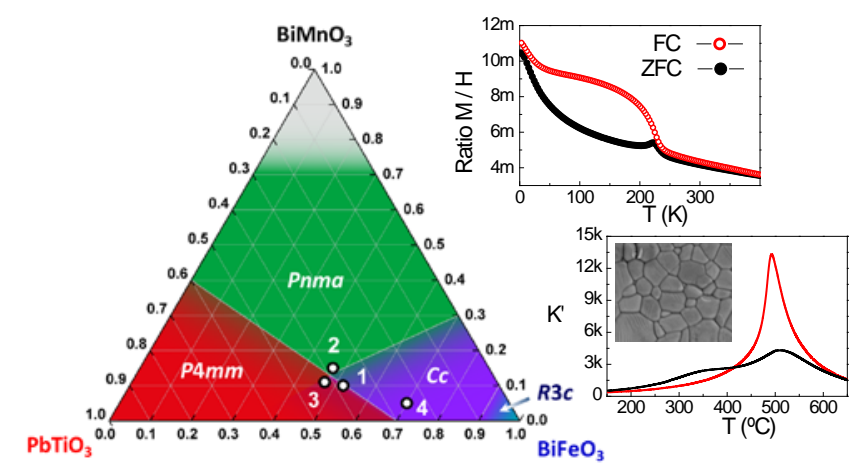

1

4

5

6

7

8

10

11

12

13

14

15

16

17

18

19

20

21

22

23

24

25

26

27

28

29

30

31

32

33

34

35

36

37

38

39

40

41

42

43

44

45

46

47

48

49

50

51

52

53

54

55

56

57

58

59

60

ACS Paragon Plus Environment 